\title{
Outcomes of 23-gauge pars plana vitrectomy and internal limiting membrane peeling with brilliant blue in macular hole
}

This article was published in the following Dove Press journal:

Clinical Ophthalmology

I8 August 2011

Number of times this article has been viewed

\author{
Huseyin Sanisoglu' \\ Mehmet Sahin Sevim' \\ Betul Aktas' \\ Semra Sevim ${ }^{2}$ \\ Ahmet Nohutcu' \\ 'Haydarpașa Numune Education and \\ Research Hospital, Department of \\ Ophthalmology, ${ }^{2}$ Uskudar State \\ Hospital, Eye Clinic, Istanbul, Turkey
}

Correspondence: Mehmet Sahin Sevim Haydarpașa Numune Education and Research Hospital, Department of Ophthalmology, Haydarpașa Numune, Istanbul, Kadikoy 34750, Turkey

$\mathrm{Tel}+905322312117$

Fax +90216345 4083

Email sahinsevim@hotmail.com
Purpose: The evaluation of anatomic and visual outcomes in macular hole cases treated with internal limiting membrane (ILM) peeling, brilliant blue (BB), and 23-gauge pars plana vitrectomy (PPV).

Materials and methods: Fifty eyes of 48 patients who presented between July 2007 and December 2009 with the diagnosis of stage 2, 3, or 4 macular holes according to Gass Classification who had undergone PPV and ILM peeling were included in this study. Pre- and postoperative macular examinations were assessed with spectral-domain optical coherence tomography. $23 \mathrm{G}$ sutureless PPV and ILM peeling with BB was performed on all patients.

Results: The mean age of patients was $63.34 \pm 9.6$ years. Stage 2 macular hole was determined in 17 eyes (34\%), stage 3 in 24 eyes (48\%), and stage 4 in 9 eyes (18\%). The mean follow-up time was $13.6 \pm 1.09$ months. Anatomic closure was detected in 46/50 eyes (92\%), whereas, in four cases, macular hole persisted and a second operation was not required due to subretinal fluid drainage. At follow-up after 2 months, persistant macular hole was detected in one case and it was closed with reoperation. At 12 months, an increase in visual acuity in 41 eyes was observed, while it remained at the same level in six eyes. In three eyes visual acuity decreased. There was a postoperative statistically significant increase in visual acuity in stage 2 and 3 cases $(P<0.05)$, however, no increase in visual acuity in stage 4 cases was observed.

Conclusion: PPV and ILM peeling in stage 2, 3, and 4 macular hole cases provide successful anatomic outcomes, however, in delayed cases, due to photoreceptor loss, it has no effect on functional recovery. BB, used for clarity of ILM, may be beneficial due to its low retinal toxicity.

Keywords: macular hole, internal limiting membrane, ILM peeling, brilliant blue

\section{Introduction}

Tangential tractions on the vitreomacular interface are usually responsible for the development of idiopathic macular holes. The prevalence is 3.3/1000 and it shows a strong female predominance..$^{1}$ In the past, it was known as a rare, untreatable disorder leading to central loss of vision. In 1991, Kelly and Wendel ${ }^{2}$ reported that idiopathic macular holes could be closed by vitrectomy and gas tamponade. With a better understanding of the pathogenesis of macular hole development and innovations in macular surgery, the rate of anatomical and functional success increased. One of the important developments in the surgical approach is peeling of the internal limiting membrane (ILM). Some authors have argued that ILM peeling has beneficial effects on the surgical outcome, ${ }^{3,4}$ whereas others have stated that this approach does not affect surgical success, ${ }^{5,6}$ and may lead to complications by increasing the surgery duration. ${ }^{7,8}$ 
The ILM is formed by Müller cell extensions and functions as a kind of basal membrane between retina and vitreus, acting as a surface for glial cell proliferation. Vitreoretinal interface changes due to cellular proliferation lead to ILM distortion and eventually to the development of epiretinal membrane (ERM), macular hole, and recurring macular edema. ${ }^{9}$ With the removal of the ILM, successful results may be obtained in surgical treatment of such vitreoretinal diseases. The most difficult aspect of surgery is due to the tight attachment of the ILM to the retina and its extreme thinness and transparent nature. To increase the visibility of the ILM, several vital dyes have been used recently. Indocyanine green (ICG) and trypan blue have been used by many researchers in peeling of the ERM and ILM. There are different opinions on the amount and concentration of dye required, and exposure duration in the vitreous space. In many studies, because of intraretinal accumulation of ICG and its toxic effects on retinal pigment epithelium, visual field defects after surgery and possible optical nerve atrophy have been considered. ${ }^{8,10,11}$ Recently, brilliant blue (BB) has been used in preclinical studies as it has minimal toxic effect and provides effective membrane staining. ${ }^{9,12}$ In this study, the anatomical and visual outcomes of pars plana vitrectomy (PPV) and ILM peeling with BB in the treatment of idiopathic macular holes has been examined.

\section{Methods and materials}

Fifty eyes of 48 patients who had 23 G PPV and ILM peeling as a treatment for macular holes between July 2007 and December 2009 were retrospectively evaluated in the authors' clinic. All patients underwent measurement of bestcorrected visual acuity and intraocular pressure, anterior segment and fundus examinations before surgery. The possible merits and risks of the treatment were explained to the patients, and informed consent was obtained from all patients in accordance with the Helsinki Declaration. Inclusion criteria were: diagnosis using noncontact-lens biomicroscopy and optical coherence tomography (OCT) of stages 2, 3, and 4 idiopathic macular hole according to the Gass classification. Exclusion criteria were: trauma history; previous macular surgery, rhegmatogenous retinal detachment together with macular hole; myopia higher than 10D; macular hole for more than 2 years; and previous retinal vessel disease. Macular examination was performed before surgery and 1,3, and 6 months after surgery using spectral OCT (Optovue Inc, Fremont, CA).

All patients had a $23 \mathrm{G}$ transconjunctival three port pars plana vitrectomy. In four eyes having both macular hole and
ERM, both ILM and ERM peeling were performed. To visualize the ILM, $0.3 \mathrm{~mL}$ BB was used in all patients. At the end of the surgery, $16 \% \mathrm{C}_{3} \mathrm{~F}_{8}$ gas was injected into 28 eyes (56\%) and $18 \% \mathrm{C}_{2} \mathrm{~F}_{6}$ gas into 22 eyes (44\%).

Follow-up time points included 1-day, 1-week, 1-month, 3-month, and 6-month postsurgical evaluations and thereafter visits at 3-month intervals. Best-corrected visual acuity, intraocular pressure, and complications were recorded for each visit. Anatomical and functional outcomes of macular hole patients who underwent $23 \mathrm{G}$ PPV and ILM peeling with BB were evaluated. Cases in different macular hole stages were compared in terms of anatomical and functional results.

\section{Surgical technique}

All operations were performed under local anesthesia. Following the introduction of a $23 \mathrm{G}$ infusion cannula at the inferotemporal site, other $23 \mathrm{G}$ trochars were inserted at the superotemporal and superonasal quadrants. Imaging systems used were the Volk MiniQuad XL (Volk Optical Ltd, Mentor, $\mathrm{OH}$ ) during vitrectomy and Volk Central Retina (Volk Optical Ltd) during ILM peeling. After core vitrectomy, triamcinolone acetonide (Kenacort-A; Bristol Myers Squibb, New York, NY) was used to remove the posterior hyaloid. The posterior hyaloid was removed from the optic nerve head via high vacuum. Brilliant blue $0.3 \mathrm{~mL}$ (Fluoron Gmbh, Ludwigsfeld, Germany) was injected to the posterior pole via a $23 \mathrm{G}$ dualbore cannula. After 60 seconds, peeling of the ILM was performed using a $23 \mathrm{G}$ diamond-dusted membrane scraper (Synergetics Inc, Fort Collins, CO) and 23 G Eckardt endgripping forceps (DORC, Zuidland, The Netherlands) for an area of at least 3 disc diameters. After liquid-air exchange, air-gas exchange was performed $\left(16 \% \mathrm{C}_{3} \mathrm{~F}_{8}\right.$ or $\left.18 \% \mathrm{C}_{2} \mathrm{~F}_{6}\right)$. None of the patients required sutures. Patients were asked to maintain a facedown position for 1 week.

\section{Results}

The patient group consisted of 33 (66\%) female and 17 (34\%) male subjects (mean age $\pm \mathrm{SD} ; 63.34 \pm 9.6$ ). Of these cases, 31 were phakic $(62 \%)$ and 19 were pseudophakic $(38 \%)$. Preoperative OCT examination revealed that, according to Gass classification, 17 eyes (34\%) had stage 2 macular holes, 24 eyes (48\%) had stage 3, and 9 eyes (18\%) had stage 4 . Four eyes with stage 2 macular holes also had an ERM. The mean follow-up period after surgery was $13.6 \pm 1.09$ months. Demographic characteristics of patients are given in Table 1.

Anatomic success was assessed by the closure of the hole on OCT imaging and the withdrawal of subretinal fluid. 
Table I Patient $(\mathrm{n}=50)$ characteristics

\begin{tabular}{ll}
\hline Gender & \\
Male $(\mathrm{n})$ & 17 \\
Female $(\mathrm{n})$ & 33 \\
Age (years) & \\
$\quad$ Mean \pm SD & $63.34 \pm 9.6$ \\
$\quad$ Range & $39-82$ \\
Mean follow-up (months) & $13.6 \pm 1.09$ \\
Lens status before surgery & \\
Phakic (n) & 31 \\
Pseudophakic (n) & 19 \\
Stage of macular hole & \\
$\quad$ Stage 2 & $17(34 \%)$ \\
Stage 3 & $24(48 \%)$ \\
Stage 4 & $9(18 \%)$ \\
\hline
\end{tabular}

Abbreviations: $n$, number; SD, standard deviation.

The hole was closed in $46(92 \%)$ of the 50 eyes after surgery but not closed in $4(8 \%)$ eyes. When postoperative OCT controls revealed that subretinal fluid had disappeared, there was no need for a second surgery. Hole persistence was observed in only one patient 2 months after the surgery and it was closed by reoperation. Figure 3 shows pre- and postoperative third-month spectral OCT imaging of a patient with a stage 4 macular hole. Anatomic success was not different among the three groups.

The mean best-corrected visual acuity of all patients before surgery was $0.71 \pm 0.25 \log$ MAR. Postoperative mean bestcorrected visual acuity (and comparison with preoperative values) was obtained as: $0.48 \pm 0.26$ at 3 months $(P<0.05)$, $0.52 \pm 0.27$ at 6 months $(P<0.05), 0.42 \pm 0.30$ at 9 months $(P<0.05)$, and $0.41 \pm 0.31$ at 12 months $(P<0.05)$. When assessed together, the final visits (at 12 months) demonstrated that visual acuity had increased in 41 eyes ( $82 \%)$, whereas, in 6 eyes (12\%), visual acuity remained unchanged. Because of recurrent macular holes, three cases showed a decrease in visual acuity. Two of these three cases had stage 4 macular holes, and one had a stage 3 macular hole. Best-corrected visual acuity results of patients before and after surgery are given in Figure 1 and Table 2. When evaluated according to the stage of macular hole, in stage 2 patients, all measurements of visual acuity after surgery showed that it was significantly higher when compared with preoperative measurements $(P<0.05)$. Increase in visual acuity between 6 and 12 months after surgery was statistically significant due to cataract surgery $(P<0.05)$.

In stage 3 patients, preoperative visual acuity compared with postoperative 3-month scores showed an increase, but this was not statistically significant $(P=0.056)$. During the postoperative period, visual acuity reduced between months 3 and 6 due to cataract development. In patients who underwent phacoemulsification after 6 months, visual acuity increased again. Therefore, comparisons of postoperative 9-12-month values showed significant increases $(P<0.05)$.

In contrast, in stage 4 patients, visual acuity scores of all time points after surgery failed to reach statistically significant levels with respect to preoperative values. Visual acuity changes of these three groups are shown comparatively in Figure 2. An increase during the first month was not expected because of the gas endotamponade. Therefore, the first month visual acuity measurements were excluded from analysis. In 22 phakic patients, visual acuity increased after cataract surgery at 6 months.

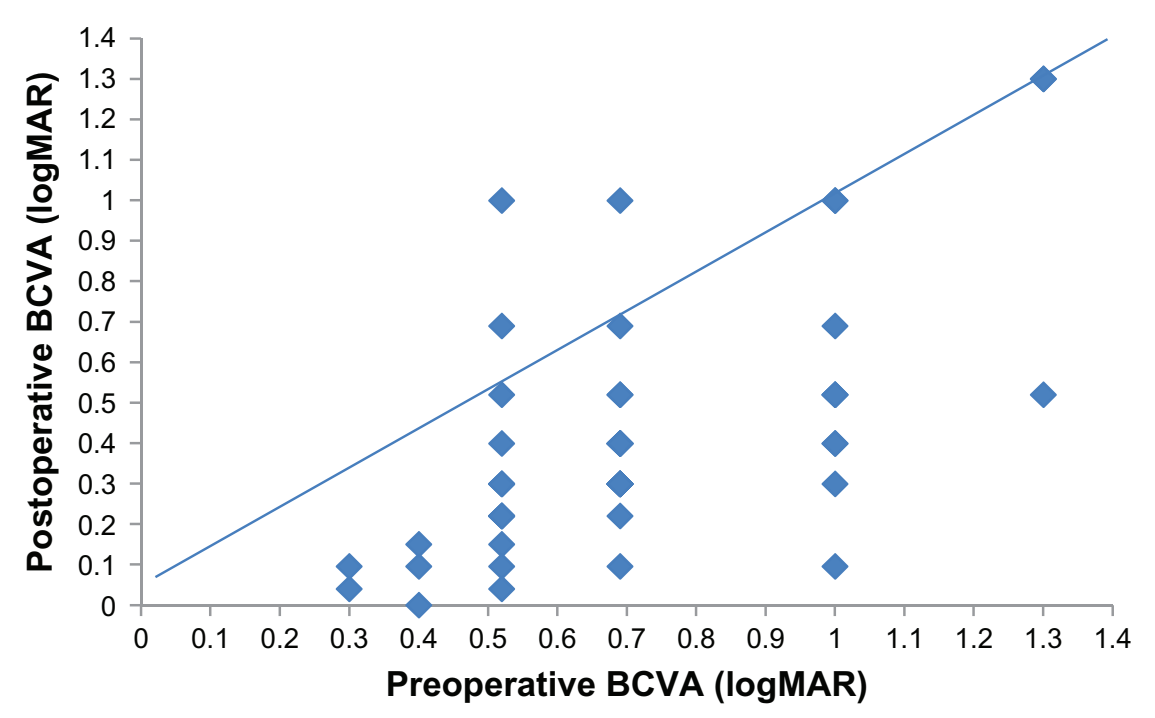

Figure I Best-corrected visual acuity (BCVA) of all patients before and after surgery (12 month). 
Table 2 Visual acuity (logMAR)

\begin{tabular}{lllllll}
\hline $\begin{array}{l}\text { Macular } \\
\text { hole stage }\end{array}$ & Preop & $\begin{array}{l}\text { Postop } \\
\text { 3 months }\end{array}$ & $\begin{array}{l}\text { Postop } \\
\text { 6 months }\end{array}$ & $\begin{array}{l}\text { Postop } \\
\text { 9 months }\end{array}$ & $\begin{array}{l}\text { Postop } \\
\text { I2 months }\end{array}$ & $\begin{array}{l}\text { Statistical } \\
\text { significance (P) }\end{array}$ \\
\hline 2 & $0.60 \pm 0.21$ & $0.33 \pm 0.13$ & $0.35 \pm 0.14$ & $0.22 \pm 0.12$ & $0.20 \pm 0.14$ & $<0.05$ \\
3 & $0.70 \pm 0.24$ & $0.47 \pm 0.23$ & $0.53 \pm 0.25$ & $0.43 \pm 0.27$ & $0.43 \pm 0.27$ & $<0.05$ \\
4 & $0.89 \pm 0.21$ & $0.75 \pm 0.28$ & $0.78 \pm 0.29$ & $0.75 \pm 0.32$ & $0.75 \pm 0.32$ & $=0.89$ \\
\hline
\end{tabular}

Abbreviations: preop, preoperative; postop, postoperative.

The mean preoperative visual acuity of stage 2 macular hole patients was higher than that of stage 3 or 4 patients. Consequently, the most prominent increase in visual acuity was observed in the stage 2 group after surgery. There was no significant difference between stage 2 and 3 macular hole patients in terms of anatomical and visual outcomes, but the functional successes of these two groups were significantly higher than those of stage 4 patients. Iatrogenic retinal tears developed in four patients during surgery and were successfully treated intraoperatively. In one patient, a nasal retinal tear developed near the optic nerve while removing the posterior hyaloid. One of the phakic cases had preoperative lens opacity and vitrectomy and phacoemulsification was performed together with intracapsular lens implantation. Postoperative controls revealed hypotonia in six patients, which regressed in 3 days.

\section{Discussion}

Since the first report of Kelly and Wendel ${ }^{2}$ on the treatment of macular holes by pars plana vitrectomy and gas tamponade, anatomical and functional success rates have increased with developments in vitreoretinal surgery. Previous studies reported success rates over $90 \%$ after one session of surgery ${ }^{13,14}$ and anatomical success rates as high as $100 \%$ in stage 2 or the initial phase of stage 3 macular holes. ${ }^{15}$

In histopathological studies, ${ }^{16,17}$ various surgical approaches have been proposed based on the idea that collagen-containing myofibroblasts and actin-containing cells in the structure of ILM and ERM may cause contraction and lead to hole formation or widening of an existing hole. Many studies $^{18-21}$ have reported that ILM peeling increases anatomical and functional success in the treatment of macular hole, and during the late phases it reduces reformation of the hole. Kwok et al ${ }^{18}$ compared anatomical closure of stage 3 or 4 holes in 40 patients with or without ILM peeling. Success rate was $89 \%$ in the ILM peeling group whereas it was $59 \%$ in the group without ILM peeling. The differences in anatomical closure success may be due to stage differences of macular holes, inclusion of traumatic cases, high myopic eyes, and recurrent cases.

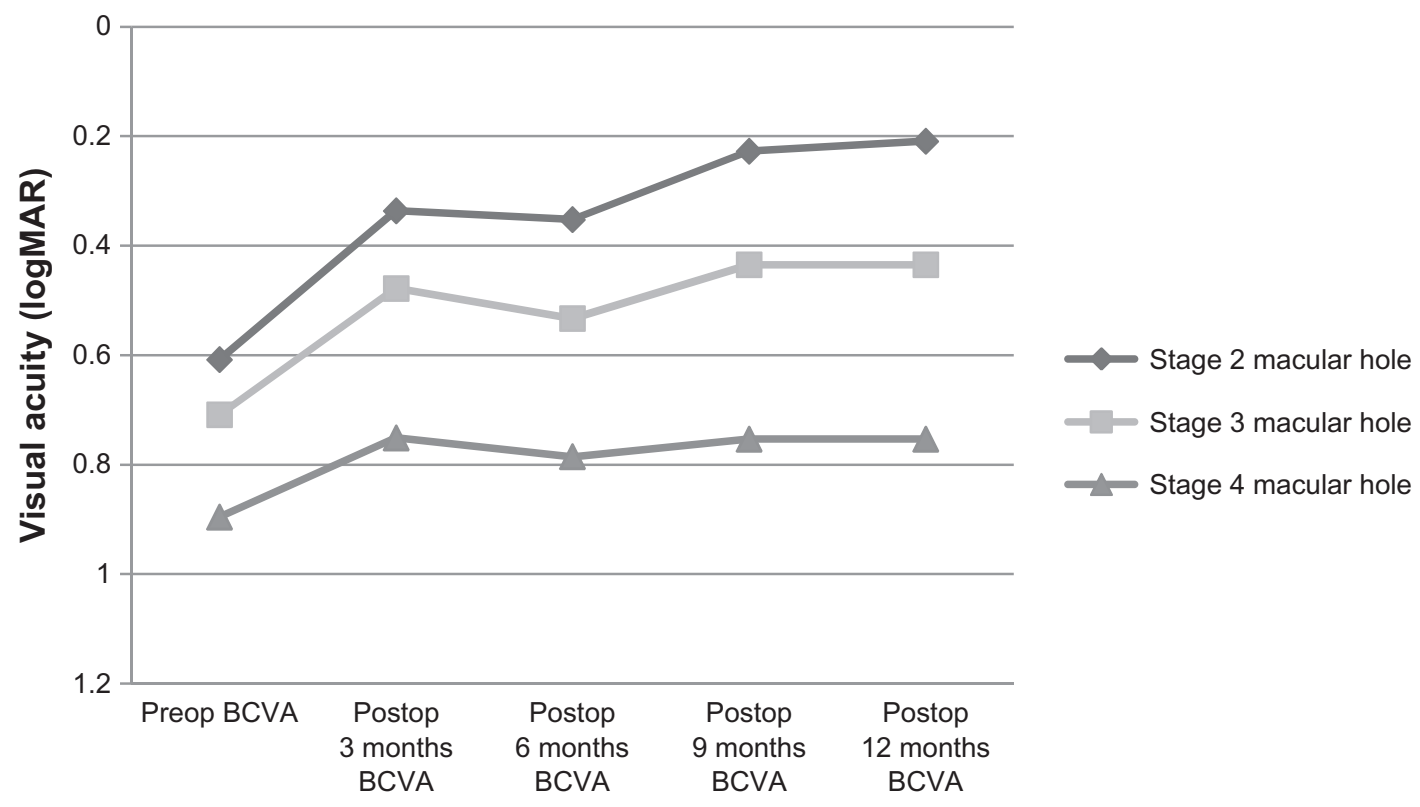

Figure 2 Best-corrected visual acuity (BCVA) (logMAR) measurements of patients with stage 2, 3 and 4 macular hole after vitrectomy and brilliant blue-assisted internal limiting membrane peeling. Stages 2 and 3 patients showed significant improvements, whereas there was no significant change in stage 4 patients.

Abbreviations: preop, preoperative; postop, postoperative. 

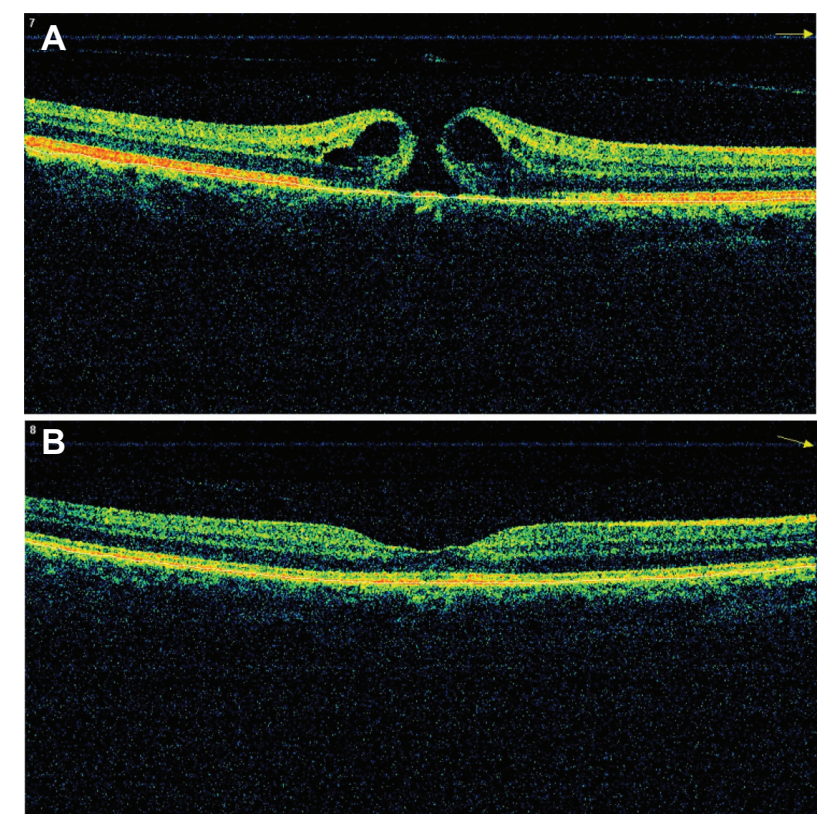

Figure 3 A representative patient with stage 4 macular hole. Preoperative (A) and postoperative 3 month (B) optical coherence tomography images.

Although there is no consensus on the effects of ILM peeling on anatomical and functional success, publications stating that ILM peeling increases hole closure are in the majority. ${ }^{22,23}$ There are several opinions regarding which patients require ILM peeling. Previous studies have stated that ILM peeling should be considered especially in patients with a hole wider than 400 microns and that is chronic (6 months or longer), traumatic, or recurring. ${ }^{21-25}$ ILM peeling was reported to increase anatomical success and prevent reopening of the hole by decreasing ERM development. ${ }^{25,26}$ Besides reports that suggest that ILM peeling increases anatomical success but not functional success, ${ }^{27}$ there are also reports that suggest functional outcomes are better in ILM peeling groups. ${ }^{18}$

In this study, ILM peeling was applied to all patients who underwent macular hole surgery. Anatomic closure was obtained in 46 (92\%) of the 50 eyes, but the hole was not closed in four patients. Visual outcomes were significantly better in stage 2 or 3 patients than in stage 4 patients $(P<0.05)$. The most prominent postoperative visual acuity improvement was obtained in stage 2 patients. The authors consider that ILM peeling improved anatomical and functional success rates in stages 2 and 3 patients whereas it had no effect on visual outcomes in stage 4 patients due to photoreceptor loss.

Cataract development is the most prevalent complication of macular hole surgery in phakic eyes. In this study group, cataract development was observed in $23(74 \%)$ of 31 patients due to an endotamponade application. Besides publications that report "early cataract surgery following macular hole surgery may increase the risk of re-opening of the hole," 28 there are also studies that report no such risk. ${ }^{29,30}$ Therefore, in patients developing cataract, phacoemulsification surgery was performed at least 6 months after macular hole surgery to prevent a recurrence.

As the thin and semitransparent structure of the ILM complicates visualization during surgery, in patients with ILM peeling, there may be small asymptomatic paracentral scotomas, irregularity in nerve fiber layers, and retinal microhemorrhages due to iatrogenic retinal trauma. ${ }^{31-36}$ Chromovitrectomy has been developed as a method to improve ILM visibility, shorten the duration of surgery, and reduce iatrogenic retinal trauma. ${ }^{36}$ Many dyes, such as indocyanine green (ICG), infracyanine green (IfCG), trypan blue (TB), BB, and triamcinolone acetonide (TA), are used to dye the ILM. Since ICG was first introduced for ILM peeling in macular hole surgery, several potential side effects have been noted. ${ }^{37,38}$ Visual field defects, retinal pigment epithelium, and ganglion cell defects are among the most reported side effects. ${ }^{26,32,33}$ Dose-dependent biochemical damage to the retinal pigment epithelium and ganglion cells, photo-oxidative cell damage due to the phototoxic properties of ICG, and retinal pigment epithelium damage due to hypoosmotic solution are considered responsible for ICG-mediated ocular toxicity. ${ }^{39-41}$ Because of the potential toxic side effects of ICG in chromovitrectomy, other vital dyes with minimal toxicity have been tried. ${ }^{32,33,38,42}$ IfCG, unlike ICG, does not contain iodine, and it is widely thought that its toxicity to the retinal pigment epithelium is less than that of ICG. ${ }^{31}$ Triamcinolone acetonide was reported as both toxic $\mathrm{c}^{43-45}$ and nontoxic ${ }^{46}$ to retinal pigment epithelium in preclinical studies. In the authors' opinion, there is an insufficient number of randomized clinical trials to make a conclusion. However, in some studies of TA-assisted ILM peeling, it was found similar to ICG. ${ }^{43,47}$ Another vital dye, TB, is recommended for ERM staining because of its high affinity for proliferation-dense intraocular tissues. ${ }^{48}$ Several preclinical studies with high-concentration TB reported toxic effects on tissue culture of retinal pigment epithelium. ${ }^{49,50}$ However, many other researchers claim that if it is used in lower concentrations, there will be no toxic effects. ${ }^{51,52}$

In this study, BB, a relatively new type of vital dye, was used to stain the ILM. It selectively dyes ILM and has no reported potential side effects or toxicity. The authors believe that it is the most effective alternative to ICG. Enaida et $\mathrm{al}^{9}$ studied ICG on rats and found that low-dose ICG administration 
resulted in no retinal cell damage but high dose ICG led to morphological damage of retinal cells. In a rat study by Hisatomi et al and Enaida et al, ${ }^{53,54}$ low dose intravitreal BB administration caused no effects on retinal cells, but in higher doses electron microscopy revealed cyst formation in the inner layers of the retina. However, there was no apoptotic cell death. The authors of this present study think that biological adaptation to BB is better than to ICG. The use of BB is easier than ICG and TB because of its granular structure and easy dissolution in intraocular irrigation. It can be sterilized by a syringe filter. Additional surgical procedures such as fluid-air exchange are required before TB administration. Dissolving ICG is more difficult because of its structure. When compared with BB, higher concentrations of ICG are required to dye the ILM. ${ }^{12}$ In addition, BB is not a fluorescent dye, so its phototoxicity is lower than ICG. The authors of this study have observed intraretinal accumulation in postoperative fundus fluorescein angiography of patients for whom ICG was used. Therefore, there may be long-term toxic effects.

\section{Conclusion}

ILM peeling in macular hole surgery provides beneficial effects on anatomical outcome, independent of disease stage. In terms of visual outcome, the highest success is obtained with stage 2 and 3 cases. It is not useful for stage 4 patients. Using BB for ILM peeling may provide beneficial effects with respect to retinal toxicity.

\section{Disclosure}

The authors report no conflicts of interest in this work.

\section{References}

1. Schurmans A, Van Calster J, Stalmans P. Macular hole surgery with inner limiting membrane peeling, endodrainage, and heavy silicone oil tamponade. Am J Ophthalmol. 2009;147(3):495-500.

2. Kelly NE, Wendel RT. Vitreous surgery for idiopathic macular holes. Results of a pilot study. Arch Ophthalmol. 1991;109(5):654-659.

3. Kwok AK, Lai TY, Man-Chan W, Woo DC. Indocyanine green assisted retinal internal limiting membrane removal in stage 3 or 4 macular hole surgery. Br J Ophthalmol. 2003;87:71-74.

4. Eckardt C, Eckardt U, Groos S, Luciano L, Reale E. Removal of the internal limiting membrane in macular holes. Clinical and morphological findings. Ophthalmologe. 1997;94(8):545-551. German.

5. Smiddy WE, Feuer W, Cordahi G. Internal limiting membrane peeling in macular hole surgery. Ophthalmology. 2001;108(8):1471-1476.

6. Benson WE, Cruikshanks KC, Fong DS, et al. Surgical management of macular holes: a report by the American Academy of Ophthalmology. Ophthalmology. 2001;108(7):1328-1335.

7. Karacorlu M, Karacorlu S, Ozdemir H. Iatrogenic punctate chorioretinopathy after internal limiting membrane peeling. Am J Ophthalmol. 2003;135(2):178-182.

8. Rodrigues EB, Meyer CH, Farah ME, Kroll P. Intravitreal staining of the internal limiting membrane using indocyanine green in the treatment of macular holes. Ophthalmologica. 2005;219(5):251-262.
9. Enaida H, Sakamoto T, Hisatomi T, Goto Y, Ishibashi T. Morphological and functional damage of the retina caused by intravitreal indocyanine green in rat eyes. Graefes Arch Clin Exp Ophthalmol. 2002;240(3): 209-213.

10. Haritoglou C, Gandorfer A, Gass CA, Schaumberger M, Ulbig MW, Kampik A. Indocyanine green-assisted peeling of the internal limiting membrane in macular hole surgery affects visual outcome: a clinicopathologic correlation. Am J Ophthalmol. 2002;134(6):836-841.

11. Maia M, Haller JA, Pieramici DJ, et al. RPE abnormalities after ILM peeling guided by ICG staining. Retina. 2004;24(1):157-160.

12. Enaida H, Hisatomi T, Hata $Y$, et al. Brilliant blue G selectively stains the internal limiting membrane. Retina. 2006;26(6):631-636.

13. Benson WE, Cruickshanks KC, Fong DS, et al. Surgical management of macular holes: a report by the American Academy of Ophthalmology. Ophthalmology. 2001;108(7):1328-1335.

14. Scott IU, Moraczewski AL, Smiddy WE, Flynn HW, Feuer WJ. Long term anatomic and visual acuity outcomes after initial anatomic success with macular hole surgery. Am J Ophthalmol. 2003;135(5):633-640.

15. Margherio RR, Margherio AR, Williams GA, Chow DR, Banach MJ. Effect of perifoveal tissue dissection in the management of acute idiopathic full-thickness macular holes. Arch Ophthalmol. 2000;118(4): 495-498.

16. Yoshida M, Kishi S. Pathogenesis of macular hole recurrence and its prevention by internal limiting membrane peeling. Retina. 2007;27(2): 169-173.

17. Yooh HS, Brooks HL Jr, Capone A Jr, L'Hernault NL, Grossniklaus HE. Ultrastructural features of tissue removed during idiopathic macular hole surgery. Am J Ophthalmol. 1996;122(1):67-75.

18. Kwok AK, Lai TY, Yuen KS, Tam BS, Wong VW. Macular hole surgery with or without indocyanine green stained internal limiting membrane peeling. Clin Experiment Ophthalmol. 2003;31(6):470-475.

19. Foulquier S, Glacet-Bernard A, Sterkers M, Soubrane G, Coscas G. Study of internal limiting membrane peeling in stage- 3 and -4 idiopathic macular hole surgery. French. J Fr Ophthalmol. 2002;25(10): 1026-1031.

20. Sheidow TG, Blinder KJ, Holekamp N, et al. Outcome results in macular hole surgery: an evaluation of internal limiting membrane peeling with and without indocyanine green. Ophthalmolgy. 2003;110(9):1697-1701.

21. Brooks HL Jr. Macular hole surgery with and without internal limiting membrane peeling. Ophthalmology. 2000;107(10):1939-1948.

22. Kuhn F. Point: To peel or not to peel, that is the question. Ophthalmology. 2002;109(1):9-11.

23. Hassan T, Williams GA. Counterpoint: To peel or not to peel: is that the question? Ophthalmology. 2002;109(1):11-12.

24. Margherio AR. Macular hole surgery in 2000. Curr Opin Ophthalmol. 2000;11(3):186-190.

25. Kumagai K, Furukawa M, Ogino N, et al. Vitreous surgery with and without internal limiting membrane peeling for macular hole repair. Retina. 2004;24(5):721-727.

26. Haritoglou C, Gass CA, Schaumberger M, Ehrt O, Gandorfer A, Kampik A. Macular changes after peeling of the internal limiting membrane in macular hole surgery. Am $J$ Ophthalmol. 2001;132(3):363-368.

27. Al-Abdulla NA, Thompson JT, Sjaarda RN. Results of macular hole surgery with and without epiretinal dissection or internal limiting membrane removal. Ophthalmology. 2004;111(1):142-149.

28. Bhatragor P, Kaiser PK, Smith SD, Meisler DM, Lewis H, Sears JE. Reopening of previously closed macular holes after cataract extraction. Am J Ophthalmol. 2007;144(2):252-259.

29. Passemand M, Yakoubi Y, Muselier A, et al. Long-term outcome of idiopathic macular hole surgery. Am J Ophthalmol. 2010;149(1): 120-126.

30. Hager A, Ehrich S, Wiegand W. Rate of reopening of macular holes following cataract operation. Ophthalmologe. 2007;104(5):388-392.

31. Farah ME, Maia M, Rodrigues E. Dyes in ocular surgery: principles for use in chromovitrectomy. Am J Ophthalmol. 2009;148(3):332-340.

32. Haritoglou C, Ehert O, Gass CA, Kristin N, Kampik A. Paracentral scotoma: a new finding after vitrectomy for idiopathic macular hole. Br J Ophthalmol. 2001;85(2):231-233. 
33. Tsuiki E, Fujikawa A, Miyamura N, Yamada K, Mishima K, Kitaoka T. Visual field defects after macular hole surgery with indocyanine greenassisted internal limiting membrane peeling. Am J Ophthalmol. 2007;143(4):704-705.

34. Ito Y, Terasaki H, Takahashi A, Yamakoshi T, Kondo M, Nakamura M. Dissociated optic nerve fiber layer appearance after internal limiting membrane peeling for idiopathic macular holes. Ophthalmology. 2005;112(8):1415-1420.

35. Christensen UC, Kroyer K, Thomadsen J, Jorgensen TM, la Cour M, Sander B. Normative data of outer photoreceptor layer thickness obtained by software image enhancing based on Stratus optical coherence tomography images. Br J Ophthalmol. 2008;92(6):800-805.

36. Da Mata AP, Burk SE, Riemann CD, et al. Indocyanine green-assisted peeling of the retinal internal limiting membrane during vitrectomy surgery for macular hole repair. Ophthalmology. 2001;108(7):1187-1192.

37. Stanescu-Segall D, Jackson TL. Vital staining with indocyanine green: a review of the clinical and experimental studies relating to safety. Eye (Lond). 2009;23(3):504-518.

38. Ferencz M, Somfai GM, Farkas A, et al. Functional assessment of the possible toxicity of indocyanine green dye in macular hole surgery. Am J Ophthalmol. 2006;142(5):765-770.

39. Iriyama A, Uchida S, Yanagi Y, et al. Effects of indocyanine green on retinal ganglion cells. Invest Ophthalmol Vis Sci. 2004;45(3):943-947.

40. Yip HK, Lai TY, So KF, Kwok AK. Retinal ganglion cell toxicity caused by photosensitizing effects of intravitreal indocyanine green with illumination in rat eyes. Br J Ophthalmol. 2006;90(1):99-102.

41. Jackson TL, Hillenkamp J, Knight BC, et al. Safety testing of indocyanine green and trypan blue using retinal pigment epithelium and glial cell cultures. Invest Ophthalmol Vis Sci. 2004;45(8):2778-2785.

42. Stanescu-Segall D, Jackson TL. Vital staining with indocyanine green: a review of the clinical and experimental studies relating to safety. Eye (Lond). 2009;23(3):504-518.

43. Nomoto H, Shiraga F, Yamaji H, et al. Macular hole surgery with triamcinolone acetonide-assisted internal limiting membrane peeling: one year results. Retina. 2008;28(3):427-432.
44. Yu SY, Damico FM, Viola F, D’Amico DJ, Young LH. Retinal toxicity of intravitreal triamcinolone acetonide: a morphological study. Retina. 2006;26(5):531-536.

45. Ruiz-Moreno JM, Montero JA, Bayon A, Rueda J, Vidal M. Retinal toxicity of intravitreal triamcinolone acetonide at high doses in the rabbit. Exp Eye Res. 2007;84(2):342-348.

46. Morrison VL, Koh HJ, Cheng L, Bessho K, Davidson MC, Freeman WR. Intravitreal toxicity of the kenalog vehicle (benzyl alcohol) in rabbits. Retina. 2006;26(3):339-344.

47. Karacorlu M, Ozdemir H, Arf Karacorlu S. Does intravitreal triamcinolone acetonide assisted peeling of the internal limiting membrane affect the outcome of macular hole surgery? Graefes Arch Clin Exp Ophthalmol. 2005;243(8):754-757.

48. Rodrigues EB, Maia M, Meyer CH, Penha FM, Dib E, Farah ME. Vital dyes for chromovitrectomy. Curr Opin Ophthalmol. 2007;18(3): $179-187$.

49. Kwok AK, Yeung CK, Lai TY, Chan KP, Pang CP. Effects of trypan blue on cell viability and gene expression in human retinal pigment epithelial cells. Br J Ophthalmol. 2004;88(12):1590-1594.

50. Rezai KA, Farrokh-Siar L, Gasyna EM, Ernest JT. Trypan blue induces apoptosis in human retinal pigment epithelial cells. Am J Ophthalmol. 2004;138(3):492-495

51. Haritoglou C, Eibl K, Schaumberger M, et al. Functional outcome after trypan blue-assisted vitrectomy for macular pucker: a prospective, randomized, comparative trial. Am J Ophthalmol. 2004;138(1):1-5.

52. Beutel J, Dahmen G, Ziegler A, et al. Internal limiting membrane peeling with indocyanine green or trypan blue in macular hole surgery: a randomized trial. Arch Ophthalmol. 2007;125(3):326-332.

53. Hisatomi T, Enaida H, Matsumoto H, et al. Staining ability and biocompatibility of brilliant blue G: preclinical study of brilliant blue $\mathrm{G}$ as an adjunct for capsular staining. Arch Ophthalmol. 2006;124(4):514-519.

54. Enaida H, Hisatomi T, Goto Y, et al. Preclinical investigation of internal limiting membrane peeling and staining using intravitreal brilliant blue G. Retina. 2006;26(6):623-630.
Clinical Ophthalmology

\section{Publish your work in this journal}

Clinical Ophthalmology is an international, peer-reviewed journal covering all subspecialties within ophthalmology. Key topics include: Optometry; Visual science; Pharmacology and drug therapy in eye diseases; Basic Sciences; Primary and Secondary eye care; Patient Safety and Quality of Care Improvements. This journal is indexed on

\section{Dovepress}

PubMed Central and CAS, and is the official journal of The Society of Clinical Ophthalmology (SCO). The manuscript management system is completely online and includes a very quick and fair peer-review system, which is all easy to use. Visit http://www.dovepress.com/ testimonials.php to read real quotes from published authors. 